\title{
Experimental model of ultrasound thermotherapy in rats inoculated with Walker-236 tumor
}

Modelo experimental de termoterapia ultrassônica em ratos inoculados com tumor de Walker-236

José Antonio Carlos Otaviano David Morano; Naylana Cordeiro ${ }^{\mathrm{II}}$; Sergio Botelho Guimarães ${ }^{\text {III; }}$ Francisco Vagnaldo Fechine-Jamacaru ${ }^{\text {IV }}$; Paulo Roberto Leitão de Vasconcelos ${ }^{\mathrm{v}}$; Manoel Odorico de Moraes Filho ${ }^{\mathrm{vI}}$

$\mathrm{O}$ artigo "Experimental model of ultrasound thermotherapy in rats inoculated with Walker-236 tumor" de autoria de José Antonio Carlos Otaviano David Morano et al, foi publicado duas vezes e, por conseguinte, retirado deste número. A publicação original está disponível em: Morano, José Antonio Carlos Otaviano David et al. Experimental model of ultrasound thermotherapy in rats inoculated with Walker-236 tumor. Acta Cir. Bras. vol.26 supl.1 São Paulo 2011

http://dx.doi.org/10.1590/S0102-86502011000700011

Atenciosamente,

Saul Goldenberg

Editor Chefe

Acta Cir Bras 